\title{
Erratum to: Chapters 55, 70, 138 and 140 in Information Science and Applications (ICISA) 2016
}

\section{Erratum to:}

Chapter 55 in: K.J. Kim and N. Joukov (eds.)

Information Science and Applications (ICISA) 2016, DOI: 10.1007/978-981-10-0557-2_55

The affiliation should be changed to "Amrita Center for Wireless Networks and Applications, Amrita Viswa Vidyapeetham, Kollam, India"

Erratum to:

Chapter 70 in: K.J. Kim and N. Joukov (eds.)

Information Science and Applications (ICISA) 2016, DOI: 10.1007/978-981-10-0557-2_70

The affiliation should be changed to "Amrita Center for Wireless Networks and Applications, Amrita Viswa Vidyapeetham, Kollam, India”

The updated original online version for this chapter can be found at DOI: $10.1007 / 978-981-10-0557-2$ _55

DOI: $10.1007 / 978-981-10-0557-2$ - 70

DOI: $10.1007 / 978-981-10-0557-2 \_138$

DOI: $10.1007 / 978-981-10-0557-2 \_140$

(C) Springer Science+Business Media Singapore 2016

E1

K.J. Kim and N. Joukov (eds.), Information Science and Applications (ICISA) 2016,

Lecture Notes in Electrical Engineering 376,

DOI: 10.1007/978-981-10-0557-2 145 


\section{Erratum to:}

\section{Chapter 138 in: K.J. Kim and N. Joukov (eds.)}

Information Science and Applications (ICISA) 2016, DOI: 10.1007/978-981-10-0557-2_138

The author name was changed to "SeungAe Kang"

The footnote was changed to "Funding for this paper was provided by Namseoul University."

\section{Erratum to:}

Chapter 140 in: K.J. Kim and N. Joukov (eds.)

Information Science and Applications (ICISA) 2016, DOI: 10.1007/978-981-10-0557-2_140

The author name was changed to "Hyuncheol Kim"

The footnote was changed to "Funding for this paper was provided by Namseoul University." 